\title{
A Decade of Live Related Donor Kidney Transplant: Experience in a Tertiary Care Hospital of Bangladesh
}

\author{
Mitra $\mathrm{P}^{\mathrm{a}}$, Hossain $\mathrm{MG}^{\mathrm{a}}$, b , Hossan $\mathrm{ME}^{\mathrm{a}}$, Khoda $\mathrm{MME}^{\mathrm{a}, \mathrm{b}}$, Rahim MAª ${ }^{\mathrm{a}}$, Hossain $\mathrm{MJ}^{\mathrm{a}}$, Billah \\ $\mathrm{MM}^{\mathrm{a}}$, Haque WMMa , Rahman $\mathrm{MA}^{\mathrm{a}}$, Iqbal $\mathrm{S}^{\mathrm{a}}$, Mansur MA
}

\begin{abstract}
Background: Kidney transplantation is the preferred treatment for end stage kidney disease (ESKD). Live related donor kidney transplant was started in BIRDEM General Hospital, Bangladesh, on $6^{\text {th }}$ November 2004. The aim of this study was to share our last 10 years' experience of live related donor kidney transplant.

Methods: A questionnaire was formed and data were collected from the hospital records. We retrospectively evaluated patients' clinical and laboratory findings.

Results: A total of 111 live related donor kidney transplants were performed from 2004 to 2014. Male:female was 2.3:1. The mean age of the recipients was $37.45 \pm 10.58$ years. The causes of ESKD were chronic glomerulonephritis $(C G N)(52,46.9 \%)$, diabetes mellitus (DM) (31, 27.9\%), hypertension $(26,23.4 \%)$, chronic pyelonephritis $(1$, $0.9 \%$ ) and obstructive nephropathy $(1,0.9 \%)$. Pre-emptive transplantation was done in $4(3.6 \%)$ patients. Patients on continuous ambulatory peritoneal dialysis and haemodialysis were 2 (1.8\%) and 105 (94.6\%) respectively. Most of the donors were siblings (55.9\%). Majority (64.9\%) had an uncomplicated recovery. The commonest complication during post-transplant hospital stay was infection (27.0\%), mostly urinary tract infection (21.6\%). Surgical failure was experienced in $1(0.9 \%)$ and acute rejection was noted in $2(1.8 \%)$ patients. Other complications were renal vein thrombosis $(1,0.9 \%)$, haemolytic uremic syndrome (1,0.9\%), acute tubular necrosis (1, 0.9\%), peri-renal collection (1, 0.9\%), pericardial effusion (1, 0.9\%) and clot retention in urinary bladder (2, 1.8\%). Mean post-transplant hospital stay was $12.39 \pm 4.27$ days. Mean duration from surgery to normalization of serum creatinine was $5.75 \pm 4.15$ days. During discharge, $71.2 \%$ patients had normal renal function (RF) with mean serum creatinine $1.03 \pm 0.15 \mathrm{mg} / \mathrm{dl}$ and $26.1 \%$ patients had gradually improving $R F$ with mean serum creatinine $2.01 \pm 1.04 \mathrm{mg} / \mathrm{dl}$. As induction, 61 (55\%) patients received basiliximab and as maintenance therapy all patients received oral prednisolone, calcinurine inhibitor and mycophenolate. In the first year of transplant, $49.5 \%$ patients suffered from infections, of which urinary tract infection was the commonest (55.9\%). Incidence of chronic allograft nephropathy in CGN, DM and hypertension patients were 25\%, $19.4 \%$ and $23.1 \%$ respectively. Graft survival at 1 year, 3 years and 5 years was $94.06 \%, 85.88 \%$ and $77.27 \%$ respectively. Patient survival at 1 year, 3 years and 5 years was $98.1 \%, 88.24 \%$ and $84.09 \%$ respectively.
\end{abstract}

Conclusions: Our results are comparable or in some aspects, even better in comparison to other centers of both developing and developed world. In a center of a developing country with limited facility and resource, these achievements are encouraging.

Key words: Graft survival, live related donor kidney transplant, patient survival.

(BIRDEM Med J 2018; 8(3): 198-202)

Author Information

Dr. Palash Mitra, Assistant Registrar, Dr. Md. Golzar Hossain, Senior Medical Officer and Transplant Co-ordinator, Dr. Md. Emtiaz Hossan, Senior Medical Officer, Dr. Mohammad Mehfuz-E-Khoda, Junior Consultant, Dr. Muhammad Abdur Rahim, Assistant Professor, Dr. Md. Jakir Hossain, Senior Medical Officer, Dr. Md. Mostarshid Billah, Assistant Professor, Dr. Wasim Md. Mohosin Ul Haque, Associate Professor, Dr. Md. Anisur Rahman, Associate Professor, Prof. Sarwar Iqbal, Professor, Prof. Md. Abul Mansur, Director.

a. Department of Nephrology and Dialysis, BIRDEM General Hospital, Dhaka, Bangladesh.

b. Transplant Unit, BADAS, Dhaka, Bangladesh.

Address of Correspondence: Dr. Muhammad Abdur Rahim, Assistant Professor, Department of Nephrology and Dialysis, BIRDEM General Hospital, Dhaka, Bangladesh, Email: muradrahim23@yahoo.com

Received: November 22, 2017

Accepted: June 30, 2018

\section{Introduction}

When the kidneys are no longer able to work at a level needed for day-to-day life, then we label the disease as end stage kidney disease (ESKD). Dialysis and kidney transplantation, of the two treatment modalities, kidney transplantation has become the preferred option for ESKD patients. In 1936, Dr. Voronoy, a Russian, reported the first human-to-human, mismatched, non related kidney transplant and in 1954 Surgeons Joseph E. Murray and John Hartwell Harrison, in collaboration with nephrologist John P. Merrill, performed the first successful kidney transplant, between identical twins, at the Peter Bent Brigham Hospital in Boston. ${ }^{1}$ Fifty years 
later, in 2004, in BIRDEM General Hospital, live related donor renal transplant was started. So far we have performed 111 live related donor kidney transplant in the last 10 years. Here we share our experiences of the past decade.

\section{Methods}

During renal transplantation, consent was taken from every patient regarding storage of all medical data and possible use for scientific research without disclosing their identity. In this study no intervention was planned and identity of the recipients was not disclosed.

Data were collected in a pre-formed questionnaire from the hospital records. We retrospectively evaluated patients' clinical and laboratory findings.

\section{Results}

In the past decade, 111 live related donor renal transplants were done in our unit. Of them, 77 (69.4\%) were male and $34(30.6 \%)$ were female. The mean age of the recipients was $37.45 \pm 10.58$ years (range 18 to 62 years). Most patients $(40,36.04 \%)$ were from the age group of 31 to 40 years (Figure 1). As cause of ESKD, highest number of patients $(52,46.9 \%)$ were suffering from chronic glomerulonephritis (CGN) and the others were diabetes mellitus (DM) $(31,27.9 \%)$, hypertension $(26,23.4 \%)$, chronic pyelonephritis (1, $0.9 \%$ ) and obstructive nephropathy $(1,0.9 \%)$. Preemptive transplantation was done in $4(3.6 \%)$ patients. Before transplantation, $2(1.8 \%)$ patients were receiving continuous ambulatory peritoneal dialysis (CAPD) and $105(94.6 \%)$ were on maintenance haemodialysis. As

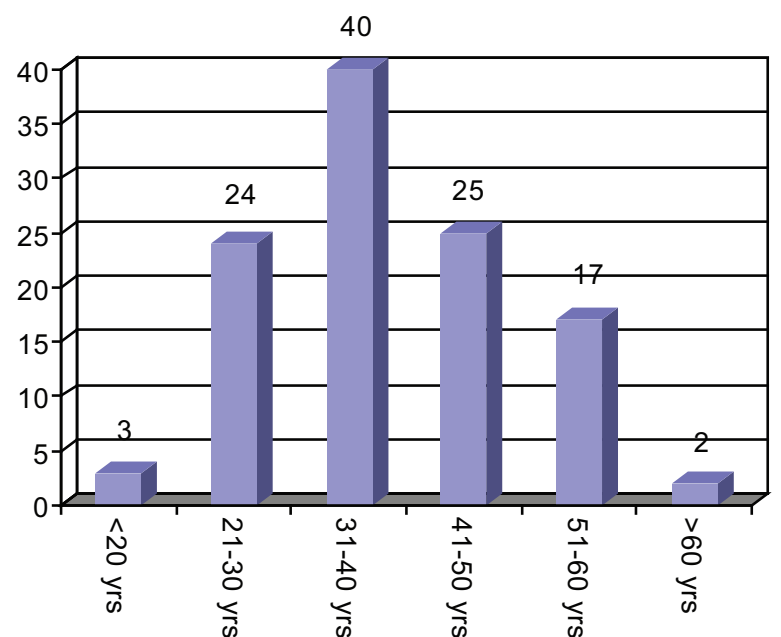

Figure 1 Age distribution of kidney transplant recipients donors, siblings stepped forward in most of the cases [brother $42(37.8 \%)$ and sister $20(18.0 \%)$ ]. Donor relationships among the rest of the cases were, mother $19(17.1 \%)$, uncle $18(16.3 \%)$, aunty $6(5.4 \%)$, wife 3 $(2.7 \%)$, father $2(1.8 \%)$ and daughter $1(0.9 \%)$. Majority of the recipients had an uncomplicated recovery (72, $64.9 \%$ ). The most common complications during posttransplant hospital stay were infections $(27.0 \%)$. A total of 30 incidences of infections were detected with the following distribution - urinary tract infection (24, $21.6 \%)$, respiratory tract infection $(2,1.8 \%)$, septicaemia $(2,1.8 \%)$, cylomegato virus infection (1, $0.9 \%$ ) and wound infection $(1,0.9 \%)$. Other complications were renal vein thrombosis $(1,0.9 \%)$, haemolytic uremic syndrome [HUS] $(1,0.9 \%)$, acute tubular necrosis [ATN] $(1,0.9 \%)$, peri-renal collection $(1,0.9 \%)$, pericardial effusion $(1,0.9 \%)$ and clot retention in urinary bladder $(2,1.8 \%)$. Surgical failure was experienced in $1(0.9 \%)$ and acute rejection was

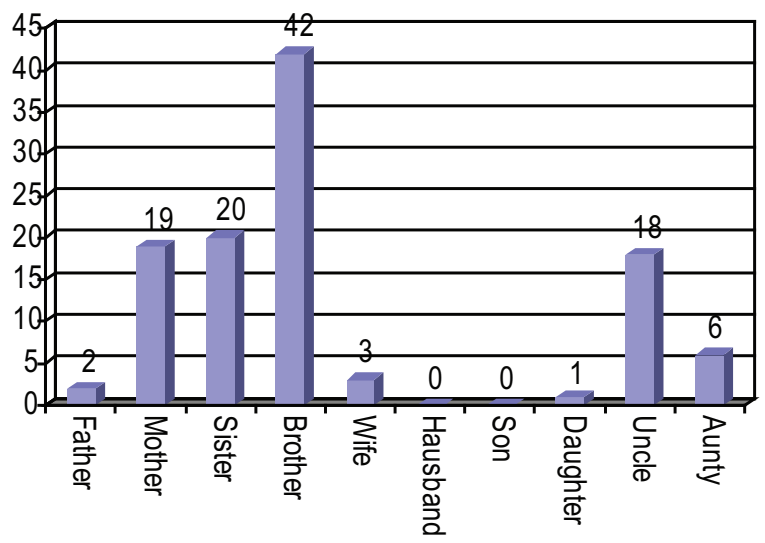

Figure 2 Donor relationship status

noted in $2(1.8 \%)$ patients. Mean post-transplant hospital stay was $12.39 \pm 4.27$ days (range 9 to 30 days). Mean serum creatinine during discharge was $1.33 \pm 0.74 \mathrm{mg} /$ $\mathrm{dl}$ (range 0.7 to $3.8 \mathrm{mg} / \mathrm{dl}$ ) and mean time from surgery to normalization of serum creatinine was $5.75 \pm 4.15$ days (range 2 to 26 days). We discharged 79 (71.2\%) patients with normal renal function (mean serum creatinine $1.03 \pm 0.15 \mathrm{mg} / \mathrm{dl})$. In $29(26.1 \%)$ patients serum creatinine was improving but did not reached normal level (mean serum creatinine $2.01 \pm 1.04 \mathrm{mg}$ / dl).

As induction, 61 (54.95\%) patients received injection basiliximab and as maintenance therapy all patients 
Table I Pattern of infection among study subjects

\begin{tabular}{lcc}
\hline Infection & Frequency & Percentage \\
\hline Urinary tract infection & 33 & 55.9 \\
Respiratory tract infection & 6 & 10.2 \\
Skin infection & 6 & 10.2 \\
Wound infection & 4 & 6.8 \\
Central nervous system infection & 2 & 3.4 \\
Alimentary tract infection & 2 & 3.4 \\
Joint & 2 & 3.4 \\
Unidentified focus & 4 & 6.8 \\
\hline
\end{tabular}

Table II Aetiological agents of infection among study subjects

\begin{tabular}{lcc}
\hline Organism & Frequency & Percentage \\
\hline Bacteria & 39 & 66.1 \\
Escherectia coli & 21 & 35.6 \\
Pseudomonas sp & 8 & 13.6 \\
Klebsiella sp & 4 & 6.8 \\
Acinetobacter & 2 & 3.4 \\
Staphylococcus aureus & 2 & 3.4 \\
Mycobacterium tuberculosis & 2 & 3.4 \\
Virus & 8 & 13.6 \\
Herpes zoster & 6 & 10.2 \\
Cytomegalovirus & 2 & 3.4 \\
Fungus & 4 & 6.8 \\
No isolates & 8 & 13.6 \\
\hline
\end{tabular}

received oral prednisolone, calcinurine inhibitor [ciclosporin in $51(45.96 \%)$ and tacrolimus in 60 (54.04\%) patients] and mycophenolate.

In the first year of transplant, 49 (49.5\%) patients suffered from 59 episodes of infection. The pattern and aetiological agents of infections are plotted in Table I and II respectively.
Incidence of chronic allograft nephropathy in CGN, DM and hypertension patients were 25\% (13/52), 19.4\% (6/ $31)$ and $23.1 \%(6 / 26)$ respectively.

In this center, patient and graft survival at 1 year was 98.1\% (99) and 94.06\% (95) respectively. Also patient and graft survival at 5 years was $84.09 \%$ (37) and $77.27 \%$ (34) respectively. Five (4.5\%) patients dropped out from follow-up.

\section{Discussion}

The outcome for kidney transplant recipients has markedly improved since it was started. This improvement of outcome is due to various reasons. First, development of more improved criteria for selection of recipients as well as donors; second, development of appropriate immunosuppressive protocol; third, discovery and usage of new and less toxic but efficient immunosuppressive drugs; forth, introducing induction therapy; and lastly awareness and development of management strategy about infections and other posttransplant complications of the recipients. ${ }^{3,6-8,11,14}$ These developments lead us to select more suitable patients as recipients and perfectly matched healthy donors for them. Fewer cases of acute rejection are faced now-a-day, due to appropriate induction therapy and immunosuppressive protocol. The induction therapy also has a role in long term graft survival along with usage of newer, effective and less toxic drugs as post transplant immunosuppressive agents. ${ }^{15}$ Awareness about comorbid conditions and infection and other posttransplant complications help us to address them promptly and properly, so that the patient as well as the graft longevity is less influenced. The reflection of all these can be seen in the results of our unit.

The graft survival at 1 and 5 years ranges from $91 \%$ to $98.3 \%$ and $68 \%$ to $92.5 \%$ respectively in different transplant centers of the world. On the other hand, patient survival of these centers at 1 and 5 years ranges from $97 \%$ to $99.4 \%$ and $82.2 \%$ to $93.7 \%$ respectively. Our graft and patient survival at 1 year was $94.1 \%$ and $98.1 \%$ respectively and at 5 years was $77.3 \%$ and $84.1 \%$ respectively, which is comparable to or, in some aspects, even better in comparison to other centers of both developing and developed world (Table III and Table IV). 
Table III Comparison of graft survival of live related donor kidney transplant in different studies

\begin{tabular}{lccc}
\hline & 1 year & 3 years & 5 years \\
\hline BIRDEM (Current study) & $94.1 \%$ & $85.9 \%$ & $77.3 \%$ \\
USA $^{2}$ & $96.3 \%$ & $89.6 \%$ & $81.4 \%$ \\
SIUT, Pakistan $^{3}$ & $92 \%$ & - & $85 \%$ \\
IKDRC-ITS, India $^{4}$ & $90.9 \%$ & - & $74.1 \%$ \\
Ahwaz Jundishapur University's Transplantation centers, Iran $^{5}$ & $94 \%$ & - & $74 \%$ \\
University of Maryland, Baltimore, Maryland $^{6}$ & $93.1 \%$ & - & $82.9 \%$ \\
University of Wisconsin Medical School $^{7}$ & - & - & $78.8 \%$ \\
School of Medicine of Botucatu, Brazil $^{8}$ & $97.6 \%$ & - & $88.6 \%$ \\
Shiraz Organ Transplantation Center, Iran $^{9}$ & $96.6 \%$ & $93.7 \%$ & $88.9 \%$ \\
Namazi hospital, Iran $^{10}$ & $98.3 \%$ & $96.4 \%$ & $92.5 \%$ \\
Govt. General Hospital, Indiaa $^{11}$ & $92 \%$ & $82 \%$ & $75 \%$ \\
Hydrabad, India $^{12}$ & $91 \%$ & - & - \\
South india $^{13}$ & $93.1 \%$ & - & $68 \%$ \\
\hline
\end{tabular}

Table IV Comparison of patient survival of live related donor kidney transplant in different studies

\begin{tabular}{lccc}
\hline & 1 year & 3 years & 5 years \\
\hline BIRDEM (Current study) USA $^{2}$ & $98.1 \%$ & $88.2 \%$ & $84.1 \%$ \\
SIUT, Pakistan $^{3}$ & $98.5 \%$ & $95.3 \%$ & $91.0 \%$ \\
IKDRC-ITS, India $^{4}$ & $97 \%$ & - & $88 \%$ \\
Ahwaz Jundishapur University's Transplantation centers, Iran $^{5}$ & $93.5 \%$ & - & $82.2 \%$ \\
University of Maryland, Baltimore, Maryland $^{6}$ & $97 \%$ & - & $84 \%$ \\
University of Wisconsin Medical School $^{7}$ & $96.8 \%$ & - & $90.4 \%$ \\
School of Medicine of Botucatu, Brazil $^{8}$ & - & - & $89.5 \%$ \\
\end{tabular}

After 10 years, the reflection of outcome of live related donor renal transplant in a center of a developing country like ours, with limited facility and resources, is still encouraging. During these 10 years we have to construct a smooth platform to face this type of advanced challenges and overcome the restriction of resources. This will encourage us to provide better and advanced management to the emerging number of ESKD patients with success.

Conflicts of interest: Nothing to declare.

\section{References}

1. National Kidney Foundation. Milestone in Organ Transplantation. Available form: https://www.kidney.org/ transplantation/transaction/Milestones-Organ-Transplantation (assessed November 1, 2017)
2. OPTN/SRTR 2009 Annual Report.

3. Rizvi SAH, Naqvi SAA, Zafar MN, Akhtar SF. A Kidney Transplantation Model in a Low Resource Country: An Experience. From Pakistan. Kidney International Supplement 2013;3:236-40.

4. Kute VB, Shah PR, Vanikar AV, Gumber MR, Goplani KR, Patel HV, et al. Long-term Outcomes of Renal Transplants from Spousal and Living-related and Other Living-unrelated Donors: A Single Center Experience. J Assoc Physicians India 2012;60:24-27.

5. Shahbazian H, Hajiani E, Ehsanpour A. Patient and graft survival of kidney allograft recipients with minimal Hepatitis C virus infection: a case-control study. Urol J 2008; 5 : $178-83$.

6. Foster CE, Philosophe B, Schweitzer EJ, Colonna JO, Farney AC, Jarrell B, et al. A Decade of Experience with Renal Transplantation in African-American. Annals of Surgery 2002:236:794-805. 
7. D'Alessandro AM, Sollinger HW, Knechtle SJ, Kalayoglu M, Kishen WA, Uehling DT, et al. Living Related and Unrelated Donors for Kidney Transplantation A 28-Year Experience. Annals of Surgery 1995:222:353-64.

8. Andrade LGM, Garcia PD, Contti MM, Silva AL, Banin VB, Daurte JC, et al. The 600 Kidney Transplants Performed at the Botucatu Medical School Hospital - UNESP: Changes Over Time. J Bras Nephrol 2014;36(2):194-200.

9. Hassanzadeh J, Hashiani AA, Rajaeefard A, Salahi H, Khedmati E, Kakaei F, et al. Long-term survival of living donor renal transplants: A single center study. Indian J Nephrol 2010; 20: 179-84.

10. Hashiani AA, Rajaeefard AR, Hassanzade J, Salahi H, Nikeghbalian S, Janghorban P, et al. Graft Survival Rate of Renal Transplantation: A Single Centre Experience, (19992009). Iran Red Crescent Med J 2011;13:392-97.
11. Abraham G, John GT, Shroff S, Fernando EM, Reddy YNV. Evolution of Renal Transplantation in India Over The Last Four Decades. NDT-Plus 2010;3:203-7.

12. Chelluri LK, Vasantha A, Ratnakar KS. Impact of Ethnicity, Donor Status and HLA Matching on Renal Allograft Survival: A Single Centre Study. Saudi J Kidney Dis transpl 2009; 20:995-97.

13. Ali AAM, Abraham G, Khanna P, Ojha A, Dhillon M, Kumar $\mathrm{KVSH}$, et al. Renal transplantation in the elderly: South Indian experience. Int Urol Nephrol 2011; 43: 265-71.

14. Matas AJ, Payne WD, Sutherland DER, Humar A, Gruessner RWG, Kandaswamy R, et al. 2,500 Living Donor Kidney Transplants: A Single-Center Experience. Annals of Surgery 2001:234:149-64

15. Koch M, Becker T, Lueck R, Neipp M, Klempnauer J, Nashan B. Basiliximab Induction Therapy in Kidney Transplantation: Benefits For Long Term Allograft Function After 10 Years? Biologics: Targets \& Therapy 2009:3:51-56. 